\title{
SCIDoC
}

\author{
International Journal of Dentistry and Oral Science (IJDOS) \\ ISSN: 2377-8075
}

\section{Association Between Orthodontic Treatment And Apical Root Resorption}

Research Article

Meera Theenathayalan ${ }^{1}$, Mahalakshmi ${ }^{*}$, Deepak. $S^{3}$

${ }^{1}$ Saveetha Dental college and Hospitals, Saveetha Institute of medical and Technical Sciences, Saveetha University, Chennai, India.

${ }^{2}$ Senior Lecturer, Department of Conservative Dentistry and Endodontics, Saveetha Dental College and hospitals, Saveetha Institute of Medical and Technical Sciences, Saveetha University, Chennai, India.

${ }^{3}$ Senior Lecturer, Department of Conservative Dentistry and Endodontics, Saveetha Dental College and hospitals, Saveetha Institute of Medical and Technical Sciences, Saveetha University, Chennai, India.

\section{Abstract}

Apical root resorption and orthodontic treatment is most unfavourable sequelae, which is very hard to predict. There is a difference in the prevalence, indicating the influence of host factors. For severe root resorption, the whole process of orthodontic treatment for root resorption should be periodically assessed. The aim of our study was to find the association between post orthodontic treatment and apical root resorption. Data collection was done and entered in the excel sheet. Parameters assessed were age, gender, teeth no. and apical root resorption for post orthodontic treatment. The data collection was tabulated in excel and data analysis was done using SPSS software. The association between study variables was calculated using the chi-square test. The result showed 20 individuals showing root resorption in both arch. Few individuals reported with resorption only in upper arch or lower arch only. The chi square test showed negative correlation between gender and teeth no. (P value $>0.05)$. Within the limitations of our study, it can be concluded that the amount of forces and movement to be evaluated periodically. The earliest stages to root resorption can be stopped and avoided.

Keywords: Apical Root Resorption; Brackets; Orthodontic Treatment.

\section{Introduction}

Apical root resorption after orthodontic treatment is an unfavourable sequelae, which is different to predict and repair. there's a private difference within the prevalence, indicating the influence of host factors. For the prevention of severe root resorption, the progress of root resorption should be periodically assessed on radiographs taken during treatment . Root resorption related to orthodontic treatment has been recognized since the report. Later, Massler and Malone [1, 2] found root resorption in 86.4 per cent of orthodontic patients. Risks for root resorption like systemic factors, treatment mechanics, treatment period, age, root shape , density of alveolar bone, and oral habits are investigated [3-6]. Root apex also as lateral surfaces of the basis can resorbe however just apical root resorption are often shown by means of radiological examination. Usually treatment doesn't cause clinically significant root resorption however microscopic changes appear on the teeth roots, which are difficult to detect in radiological images. Root resorption induces root shortening and weakening of teeth arch and this is often vital for successful treatment. These procedures are the previous research protocols for the access of the basis resorption. The treatment procedure students evaluated risk factors that root resorption in terms of the amount of subjects, which can be led to in current interpretation because patients with an equivalent degree of resorption have a special number of teeth with resorption [7-9]. Severe root resorption during treatment (more than $1 / 4$ of the basis length, $>5 \mathrm{~mm}$ ) occurs very rarely, just in 1-5 you look after patients [6]. Analysis and assessment of things inducing root resorption would simplify timely diagnosis of root resorption and would help avoid complications impacted by it. Knowing risk factors for root resorption would help the orthodontist to assess a patient upon planning treatment and to settle on the simplest method for treatment. Furthermore, no students have evaluated treatment factors relevant to severe root resorption altogether. The dentistry of the alveolar bone plays a

\section{*Corresponding Author:}

Dr.Mahalakshmi,

Senior Lecturer, Department of Conservative Dentistry and Endodontics, Saveetha Dental College and hospitals, Saveetha Institute of Medical and Technical Sciences, Saveetha University, Chennai, India.

Tel: +919003080462

E-mail: mahalakshmij.sdc@saveetha.com

Received: May 28, 2021

Accepted: June 16, 2021

Published: July 02, 2021

Citation: Meera Theenathavalan, Mahalakshmi, Deepak. S. Association Between Orthodontic Treatment And Apical Root Resorption. Int J Dentistry Oral Sci. $2021 ; 8(7): 2916-2919$. doi: http://dx.doi.org/10.19070/2377-8075-21000591

Copyright: Mahalakshmi ${ }^{\circ}$ 2021. This is an open-access article distributed under the terms of the Creative Commons Attribution License, which permits unrestricted use, distribution and reproduction in any medium, provided the original author and source are credited. 
serious role within the resorption of the basis to classify the prevalence and degree of root resorption induced by treatment with apical regard to orthodontic treatment factors. [10] The idea for this study stemmed from the current interest in our community. Previously our team has a rich experience in working on various research projects across multiple disciplines [11-15]. So the aim of our study was to find the association between post orthodontic treatment and apical root resorption.

\section{Materials And Methods}

This study was approved by the research ethics committee of saveetha dental college. The dental records of 120 patients who reported to the clinic for post orthodontic treatment were investigated by collecting the data entering in the excel sheet. The male and female distribution among the study population was evaluated. The collection of data was divided on 4 parameters, the age of the patient, the gender of the patient, teeth number and root resorption post orthodontic treatment. After grouping the parameters, data copied to the software and statistical analysis was carried out. Statistical analysis was done using IBM SPSS software. The significance level was at 0.5. Descriptive analysis and chi-square tests were done. Graphs were tabulated. Inclusion Criteria : Patients of age group 0-30 years were included, and both male and females were included. Exclusion Criteria : Other than root resorption as post orthodontic complication, other post orthodontic complications were excluded.

\section{Results And Discussion}

The study was carried out for 120 patients who reported for orthodontic treatment, out of which 20 patient's post orthodontic treatment radiographs revealed apical root resorption. The most commonly affected age group was $10-15$ years, followed by $16-$ 20 years. Percentage of males and females among the population were $75 \%$ and $25 \%$ respectively. The most affected one in the sites were both arches, most commonly seen in 10-15 years age group patients.

Association between age and teeth no. with root resorption showed $\mathrm{p}$ - value to be 0.222 , which showed a negative correlation between two parameters (Graph 2). Association between age and teeth no. in patients with root resorption showed $\mathrm{p}$ - value to be 0.461 , which showed a negative correlation between two parameters (Graph 1).

Based on the evaluation of the various parameters, for the info collected were estimated. All the successful findings were incorporated inside the info and therefore the SPSS software results. Radiographs are commonly used as a diagnostic and for root resorption. It's different to develop a uniform technique to match the teeth different times tooth movement makes it harder to assess the precise amount of root less especially when the tooth is torqued or tapered.

There can be many reasons for a tooth to undergo resorption,

Figure 1. Bar graph showing the association between the gender of the patient and no. of the patients who reported with root resorption post the orthodontic treatment. The $\mathrm{X}$ axis denotes the gender of the patient and the teeth no. $\mathrm{Y}$ axis represents the number of the patients who reported with root resorption post orthodontic treatment. It was found that both $\operatorname{arch}($ Blue) resorption was more common in males and females than the single arch [either upper(Green) or lower $\operatorname{arch}($ Red)] with root resorption. Chi square statistical test was done and the association was found to be not significant with p value .222 ( $P$ value - $>0.005$, statistically not significant).

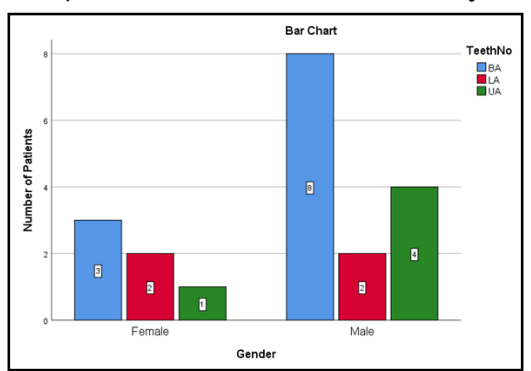

Figure 2. Bar graph shows the association between the age of the patient and no. of the patients who reported with root resorption post the orthodontic treatment. The $\mathrm{X}$ axis represents the age of the patient and the teeth no. of the patient. $\mathrm{Y}$ axis represents the number of the patients who reported with root resorption post orthodontic treatment. It was found that root resorption in both arches(Blue) were more common in the 10-15 years age group, other age groups had most commonly single arch [either upper(Green) or lower arch(Red)] root resorption. Chi square statistical test was done and the association was found to be not significant with $\mathrm{p}$ value .461 ( $\mathrm{P}$ value $->0.005$, statistically not significant).

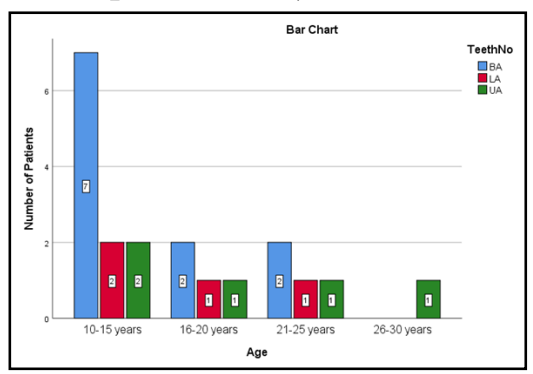


like when excessive force is applied during orthodontic treatment, due to trauma, any anatomy abnormality, etc. The patients or their parents must be told that the apical root shortening (root resorption) could also be a consequence of treatment. Its incidence is very predictable [26].

The periapical radiographs are a crucial part of orthodontic treatment for pre treatment and post treatment records. Post treatment radiographs are an important part of the entire records to access the bone/root integrity after treatment of which the patient must be told.

The treatment timing should begin as early since there's less root resorption developing roots and young patients other better muscular adaptation to occlusal changes. The quantity of force applied matters the most as the force applied can alter the position and cause changes in the tooth and bone. Adults have poorer adaptive ability and wish more rigid and longer lasting mechanical forces. The force should be intermittent and really light.

When root resorption is detected during active orthodontic treatment final goals must be reassessed. a choice should be made to terminate the treatment compromise. When necessary, applied force should be stopped and/or a bite plane should be wont to disocclude the teeth. Habits like nail biting or tongue thrusting should be stopped, since it has been shown that the basis resorption is more severe in such orthodontic patients [2]. Any sort of tooth movements can cause root resorption. it's essential to recognise the routine orthodontic tooth movement can bear anatomic and physiological limitations. If the objections of treatment are beyond these limitations, surgical interventions could also be required teeth with resorption root can function abutment bridges only which their root length exceeds the clinical crown length. If root resorption continues after appliance removal or during retention, sequential passage therapy wise lime is advisable. Gutta percha filling is the definitive therapy only after root resorption cases. it's advisable to require full mouth radiographs when receiving transfer cases [1]. Although active treatment duration evidently increases the danger of accentuated root resorption, it's obvious that the quantity and sort of tooth movement also are determinants of root resorption. Additionally, the resorptive potential seems to vary between orthodontic patients and even between different teeth within the same patient. Individual biological factors, e.g. alveolar bone density, vascularity, and tooth structure, may explain these variations. Most research has focused on maxillary incisors because they're considered more vulnerable to root resorption than other teeth]. In previous studies, of all the tooth groups, the maxillary incisors were affected most often . Earlier studies have reported radiographically clearly visible apical root resorption (more than $2 \mathrm{~mm}$ to one-third of root length) in 1.4-17 percent of incisors, whereas extreme resorption with loss of quiet one-third of the first root length was seen in just 1 to 0.4 percent of incisors. In another study, 37 per cent of the patients with apical root resorption of the maxillary incisors showed grade 2 resorption of a minimum of one incisor, indicating severe resorption with loss of one-quarter or more of root length. However, the amount of maxillary incisors wasn't determined, thus the share isn't comparable to those found in other studies. The differences within the resorption scale make the comparison even harder. Maxillary incisors are the primary teeth to reply when subjected to fixed appliance activation, which can at a minimum partly explain the high resorption potential of those teeth. It's been suggested that patients requiring premolar extractions show greater resorption potential due to significant tooth movement. The median age for root completion for the upper second premolar is 12 years for boys and 11.3 years for women, with a variety of three .3 years for boys and three .0 years for women. Thus, for a normally developing boy, the newest age for root completion might be up to fifteen 3 years. Since the typical age of the patients at the beginning of treatment was 11 years, a number of the premolars would still have had growth potential at the time of pretreatment evaluation. It's been suggested that teeth with incomplete root formation have a better resistance to root resorption than those with complete roots. Most authors have evaluated root length changes from panoramic or periapical radiographs using the long-cone paralleling technique. Since apical root resorption tends to stay active as long as treatment influences are maintained [1], special attention should tend to those patients. Careful design of force systems and well-dispersed anchorage forces, combined with respectful consideration of the other risk factors present, may help keep the danger of apical root resorption at a suitable level.Our institution is passionate about high quality evidence based research and has excelled in various fields [16-26].

\section{Conclusion}

From the study we can conclude that apical root resorption post orthodontic treatment was evident among the growing age group 10-15 years, and most commonly affected males than females. In many cases apical root resorption was seen in both the arches post orthodontic treatment. Therefore the movement of the tooth and force applied during the procedure to be monitored periodically to avoid this complication.

\section{Acknowledgement}

With Sincere gratitude, we acknowledge the staff members and students of saveetha dental college and study participants for their extended support towards the completion of research.

\section{References}

[1]. Hafeez N. Accessory foramen in the middle cranial fossa. Res J Pharm Technol. 2016 Nov 1;9(11):1880.

[2]. Krishnan RP, Ramani P, Sherlin HJ, Sukumaran G, Ramasubramanian A, Jayaraj G, et al. Surgical Specimen Handover from Operation Theater to Laboratory: A Survey. Ann Maxillofac Surg. 2018 Jul-Dec;8(2):234-238. Pubmed PMID: 30693238.

[3]. Somasundaram S, Ravi K, Rajapandian K, Gurunathan D. Fluoride Content of Bottled Drinking Water in Chennai, Tamilnadu. J Clin Diagn Res. 2015 Oct;9(10):ZC32-4.Pubmed PMID: 26557612.

[4]. Felicita AS. Orthodontic extrusion of Ellis Class VIII fracture of maxillary lateral incisor - The sling shot method. Saudi Dent J. 2018 Jul;30(3):265269.Pubmed PMID: 29942113.

[5]. Kumar S, Rahman RE. Knowledge, awareness, and practices regarding biomedical waste management among undergraduate dental students. Asian J. Pharm. Clin. Res. 2017;10(8):341.

[6]. Gurunathan D, Shanmugaavel AK. Dental neglect among children in Chennai. J Indian Soc Pedod Prev Dent. 2016 Oct 1;34(4):364.

[7]. Sneha $S$. Knowledge and awareness regarding antibiotic prophylaxis for infective endocarditis among undergraduate dental students. Asian J. Pharm. Clin. Res. 2016 Oct 1:154-9.

[8]. Dhinesh B, Lalvani JI, Parthasarathy M, Annamalai K. An assessment on performance, emission and combustion characteristics of single cylinder diesel engine powered by Cymbopogon flexuosus biofuel. Energy Convers. Manag. 2016 Jun 1;117:466-74.

[9]. Choudhari S, Thenmozhi MS. Occurrence and Importance of Posterior Condylar Foramen. LATERALITY. 2016 Aug 28;8:11-43. 
[10]. Paramasivam A, Vijayashree Priyadharsini J, Raghunandhakumar S. N6adenosine methylation (m6A): a promising new molecular target in hypertension and cardiovascular diseases. Hypertens Res. 2020 Feb;43(2):153-154. Pubmed PMID: 31578458. https://pubmed.ncbi.nlm.nih.gov/31578458/

[11]. Wu F, Zhu J, Li G, Wang J, Veeraraghavan VP, Krishna Mohan S, et al. Biologically synthesized green gold nanoparticles from Siberian ginseng induce growth-inhibitory effect on melanoma cells (B16). Artif Cells Nanomed Biotechnol. 2019 Dec;47(1):3297-3305.Pubmed PMID: 31379212.

[12]. Palati S, Ramani P, Shrelin HJ, Sukumaran G, Ramasubramanian A, Don $\mathrm{KR}$, et al. Knowledge, Attitude and practice survey on the perspective of oral lesions and dental health in geriatric patients residing in old age homes. Indian J Dent Res. 2020 Jan-Feb;31(1):22-25.Pubmed PMID: 32246676.

[13]. Saravanan M, Arokiyaraj S, Lakshmi T, Pugazhendhi A. Synthesis of silver nanoparticles from Phenerochaete chrysosporium (MTCC-787) and their antibacterial activity against human pathogenic bacteria. Microb Pathog. 2018 Apr;117:68-72.Pubmed PMID: 29427709.

[14]. Govindaraju L, Gurunathan D. Effectiveness of Chewable Tooth Brush in Children-A Prospective Clinical Study. J Clin Diagn Res. 2017 Mar;11(3):ZC31-ZC34.Pubmed PMID: 28511505.

[15]. Vijayakumar Jain S, Muthusekhar MR, Baig MF, Senthilnathan P, Loganathan S, Abdul Wahab PU, et al. Evaluation of Three-Dimensional Changes in Pharyngeal Airway Following Isolated Lefort One Osteotomy for the Correction of Vertical Maxillary Excess: A Prospective Study. J Maxillofac Oral Surg. 2019 Mar;18(1):139-146.Pubmed PMID: 30728705.

[16]. Vijayashree Priyadharsini J. In silico validation of the non-antibiotic drugs acetaminophen and ibuprofen as antibacterial agents against red complex pathogens. J Periodontol. 2019 Dec;90(12):1441-1448.Pubmed PMID: 31257588.

[17]. PC J, Marimuthu T, Devadoss P, Kumar SM. Prevalence and measurement of anterior loop of the mandibular canal using CBCT: A cross sectional study. Clin Implant Dent Relat Res. 2018 Apr 6;20(4):531-4.

[18]. Ramesh A, Varghese S, Jayakumar ND, Malaiappan S. Comparative estimation of sulfiredoxin levels between chronic periodontitis and healthy patients
- A case-control study. J Periodontol. 2018 Oct;89(10):1241-1248.Pubmed PMID: 30044495.

[19]. Ramadurai N, Gurunathan D, Samuel AV, Subramanian E, Rodrigues SJ. Effectiveness of $2 \%$ Articaine as an anesthetic agent in children: randomized controlled trial. Clin. Oral Investig. 2019 Sep;23(9):3543-50.

[20]. Sridharan G, Ramani P, Patankar S, Vijayaraghavan R. Evaluation of salivary metabolomics in oral leukoplakia and oral squamous cell carcinoma. J Oral Pathol Med. 2019 Apr;48(4):299-306.

[21]. Ezhilarasan D, Apoorva VS, Ashok Vardhan N. Syzygium cumini extract induced reactive oxygen species-mediated apoptosis in human oral squamous carcinoma cells. J Oral Pathol Med. 2019 Feb;48(2):115-121.Pubmed PMID: 30451321

[22]. Mathew MG, Samuel SR, Soni AJ, Roopa KB. Evaluation of adhesion of Streptococcus mutans, plaque accumulation on zirconia and stainless steel crowns, and surrounding gingival inflammation in primary molars: randomized controlled trial. Clin Oral Investig. 2020 Sep;24(9):1-6.Pubmed PMID: 31955271.

[23]. Samuel SR. Can 5-year-olds sensibly self-report the impact of developmental enamel defects on their quality of life? Int J Paediatr Dent. 2021 Mar;31(2):285-286. Pubmed PMID: 32416620.

[24]. R H, Ramani P, Ramanathan A, R JM, S G, Ramasubramanian A, et al. CYP2 C9 polymorphism among patients with oral squamous cell carcinoma and its role in altering the metabolism of benzo[a]pyrene. Oral Surg Oral Med Oral Pathol Oral Radiol. 2020 Sep;130(3):306-312.Pubmed PMID: 32773350.

[25]. Chandrasekar R, Chandrasekhar S, Sundari KKS, Ravi P. Development and validation of a formula for objective assessment of cervical vertebral bone age. Prog Orthod. 2020 Oct 12;21(1):38.Pubmed PMID: 33043408

[26]. Vijayashree Priyadharsini J, Smiline Girija AS, Paramasivam A. In silico analysis of virulence genes in an emerging dental pathogen A. baumannii and related species. Arch Oral Biol. 2018 Oct;94:93-98.Pubmed PMID: 30015217. 